\title{
Understanding Adaptation: Lessons from Local Adaptive Measures to Coastal Risks and Hazards - A Case Study of Kukup Water Village, Malaysia
}

\author{
Jia Yen Lai ${ }^{1 *}$, Hsien-Hsin Cheng ${ }^{2}$ \\ ${ }^{1}$ School of GeoSciences, University of Edinburgh, Scotland, UK \\ ${ }^{2}$ Department of Urban Planning, National Cheng Kung University, Tainan, Taiwan \\ *jy.lai@ed.ac.uk
}

Received : 6 January 2016 Final Version Received: 16 April 2019

Globally, rising sea levels could have the most significant impact on developing countries, which have limited adaptive capacity to face the challenges of climate change. Through a case study of Kukup water village in Malaysia, this study seeks to understand the influence of coastal risks and hazards on coastal settlements' spatial development, local construction measures for the adaptation of the coastal environment, and the implication of local adaptive measures on environmental policy and coastal management. The study used historical records and qualitative semi-structured interviews for data collection, and presented the spatial development and construction measures using an open-access 3D modelling tool, "SketchUp". The study finds that natural, socioeconomic and cultural factors have contributed to the adjustment of spatial arrangement and that local adaptive measures reflect the local perception of coastal risks and hazards. More research is needed to understand the effects of cultural factors on adaptive capacity and how cultural aspects of adaptation can contribute to the improvement of adaptive capacity that is sensitive to different social context.

Keywords: Adaption, Adaptive Capacity, Determinants, Water Settlement, Kukup

\section{INTRODUCTION}

Today, seventeen of the world's 30 most essential and most densely populated cities, including London, New York, Jakarta, Bangkok and Mumbai, are located in low-lying coastal regions within ten meters' elevation of sea level (FitzGerald, Fenster, Argow, \& Buynevich, 2008). With about half of the world's population dwelling within 60 kilometres of coastline (UNEP), sea-level rise (SLR) effects and other coastal risks are placing increasing pressure on coastal regions. Numerous climate change literature has identified potential impacts of sealevel rise to coastal cities (Dasgupta, Laplante, Meisner, Wheeler, \& Yan, 2009); however, the application and effect of adaptation remain primarily uncertain taking into account that the capacity of adaptation varies under diverse political and socio-economic conditions (Nicholls \& Tol, 2006). VanKoningsveld, Mulder, Stive, VanDerValk, and VanDerWeck (2008) examined the influence of human interventions on the low-lying environment of the Netherlands. The result suggested environmental policies and management approaches, as well as for science and technology approaches, should take account for the collective human response to address the challenges of climate change. In addition to the technical assessment of SLR impacts, researchers should pay more attention to humanrelated factors in order to achieve sustainable development.

Globally, sea level rise is likely to have the most significant impact on developing countries (Dasgupta et al., 2009), which are constrained to social and environmental resources to adapt to climate change. For effective policy planning and design, it is essential to identify the capacity of coastal communities, and the measures taken by them, to adapt coastal hazards. Using a case study of Kukup water village in Malaysia, this study seeks to understand the influence of coastal risk and hazards on coastal settlements' spatial development, the local construction measures being used to adapt the coastal environment, and the implication of local 
adaptive measures on environmental policy and coastal management.

\section{THE IMPLICATION OF HUMAN RESPONSE ON COASTAL RISKS ADAPTION}

The criterion for constituting a coastal region varies but is commonly based on geographical proximity, generally within 60 to 200 kilometres of the shoreline (Liz, 2003). Historically, human settlements tended to develop in coastal regions because of the availability of natural resources and accessibility for marine trading and transportation (Neumann, Vafeidis, Zimmermann, \& Nicholls, 2015). Coastal regions have undergone rapid socioeconomic and environmental changes in urbanisation and globalisation during recent decades (Frings, 2011; Neumann et al., 2015). Due to rapid economic growth and coastward migration in the developing countries, the coastal population has outrun the demographic and economic development in other geographical areas (Smith, 2011). For example, the growth of coastal urban areas in both China and Bangladesh is at least two times higher than the national rate (McGranahan, Balk, \& Anderson, 2007). SLRrelated effects and existing coastal hazards, such as flooding, erosion and tsunamis, have led to a focus on conservation and the restoration of ecosystems in an effort to protect coastlines from waves and storm surge (Barbier et al., 2008; Mukherjee, Balakrishnan, \& Shanker, 2009) and improve the adaptive capacity of coastal settlements (Jones, Hole, \& Zavaleta, 2012).

In the Intergovernmental Panel on Climate Change (IPCC) report on 2001, the term "adaptation" is described as "adjustments in ecological, social, or economic systems in response to actual or expected climatic stimuli and their effects or impacts. It refers to changes in processes, practices and structures to moderate potential changes or to benefit from opportunities associated with climate change" (B. Smit et al., 2001, p. 879). In the same report, "adaptive capacity" is defined as "the potential or ability of a system, region, or community to adapt to the effects or impacts of climate change". However, until recently, adaptation research tended to focus on hard-engineering structures (Aerts, 2012), such as irrigation infrastructure, sea walls and dams, rather than on the role of human or community responses to climate change adaptation; yet human response has been identified as a critical factor for the success of adaptation (Grothmann \& Patt, 2005; Barry Smit \& Wandel, 2006).
Risbey, Kandlikar, Dowlatabadi, and Graetz (1999) suggest four stages in the adaptation process: first, signal detection on deciding what is and is not adapted to; second, evaluation of the signal and its foreseeable consequences; third, decision and response to the behaviour and performance of the system; and finally, feedback on the decisions' outcomes. The adaptation stage is comparable to the structure planned adaptation proposed by Klein, Nicholls, and Mimura (1999), which includes: first, information collecting and awareness raising; second, planning and design; third, implementation; and finally, monitoring and evaluation. Although empirical studies have shown that these stages are not often consistent with the reality of adaptation (Grothmann \& Patt, 2005), those components are still useful in providing a preliminary understanding of adaptation approaches. Most importantly, these elements contribute to the consideration of adaptation in a real-life setting, where adaptation consists not only of engineering and infrastructure but also needs to take account of the societal setting.

Many adaptation studies have investigated the determinants of adaptive capacity, of which the characteristics or features of society that affect the ability to adapt and therefore their vulnerability to risks associated with climate change. The determinants of adaptive capacity are interconnected with institutional, social, economic and technological conditions in the society, and have a significant influence on the planning and implementation of adaptive measures (B. Smit et al., 2001). Urban planning scholars have identified several socioeconomic features as determinants of adaptive capacity, including economic resources, technology, information and skills, social resources, institutions and equity. Closer attention to adaptation approaches and tools that are sensitive to various socioeconomic settings are urgently needed, given that most of the coastal regions vulnerable to adverse effects of SLR and climate change are those in developing countries (Barry Smit \& Wandel, 2006).

\section{METHODOLOGY}

\subsection{METHOD AND LIMITATIONS}

This study applies a mixed approach for data collection and analysis. It uses a case study of Kukup water settlement in Johor state, Malaysia. The data collection was taken place between July and August 2013. At the initial stage, the study referred to historical records and photos to identify significant spatial changes within the 
settlement. Semi-structured interviews were conducted to clarify the natural or social factors of spatial changes, to investigate the spatial measures of adaptation to natural or social changes, to understand the rationale behind the applied spatial measures and to identify the determinants of their adaptive capacity. Finally, the study illustrates the local construction measures through 3D simulation models employing the open access tool 'SketchUp'.

This study notes two limitations: first, the earliest map that is available for this research was produced by the Department of Survey and Mapping Malaysia (JUPEM) in the year 1990. The spatial arrangement before this year was simulated, and therefore geographically inaccurate. However, high accuracy regarding geographical distribution is not essential for this study, given that a simulated spatial arrangement was used to provide additional support for the interview content. Nevertheless, it should be noted that the simulated map should only be used as a reference for a preliminary understanding of overall spatial characteristics, but not for geographic purposes. Second, the interviewees were generally opinions leaders of the village, such as village head, school principal and cultural leaders, and are mostly male.

Given that the purpose of the study is to identify measures of spatial arrangement and the rationale behind them, the study considers the village leaders as suitable informants for data collection because they possess relatively affluent information concerning the village development. However, the careful selection of interviewees may result in a biased representation of certain groups' perspectives and interests. Therefore, gender and social positions on climate change adaptation are beyond the scope of this study.

\subsection{CASE STUDY : KUKUP WATER SETTLEMENT IN JOHOR, STATE, MALAYSIA}

A settlement's spatial development is a process that transforms the space, through objects, into an observable spatial arrangement. A water settlement, which is built on stilts along the waterside, is a traditional Malaysian form of settlement that can be traced back to the $16^{\text {th }}$ century (Hassan, 2010). Buildings, roads, and facilities in a water settlement are built entirely upon artificial stilt-supported platforms, which transform a waterlogged space into a settlement. This research used two village case studies in Kukup, namely Kukup Laut and Ayer Masin to identify coastal adaptation measures at the community level (see Fig. 1). Built parallel to the Strait of Kukup, Kadir (1955) suggested that the origin of the Kukup settlements was linked to its geographical location: firstly the Kukup Island adjacent to the settlement provides shelter from waves and winds on open water, and secondly the location of the settlement was strategic to settlers to access marine resources and trading activities.

Since the mid of the $19^{\text {th }}$ century, Chinese travellers started to settle along the Straits of Kukup (Ang, 2007). Kukup Laut was built by immigrants from Kinmen County of Fujian Province, China (now named Kinmen County of Fujian Province, ROC). The village currently consists of approximately 170 units of buildings and around 120 households and 1000 inhabitants. Ayer Masin was built by immigrants from Tong'an County of Fujian Province, China (now named Tong'an District of Xiamen City, Fujian Province, PRC), and currently consists of approximately 120 units of buildings and around 80 households and 700 inhabitants. Over $90 \%$ of the inhabitants in the villages were descendants of the earliest batches of immigrants and spoke the Min Nan dialect. Considered an organically grown settlement (see Fig. 2), the case studies of Kukup provides an opportunity to understand the way of adaptation to a coastal environment that was initiated and managed by the community based on their needs and visions on the settlement.

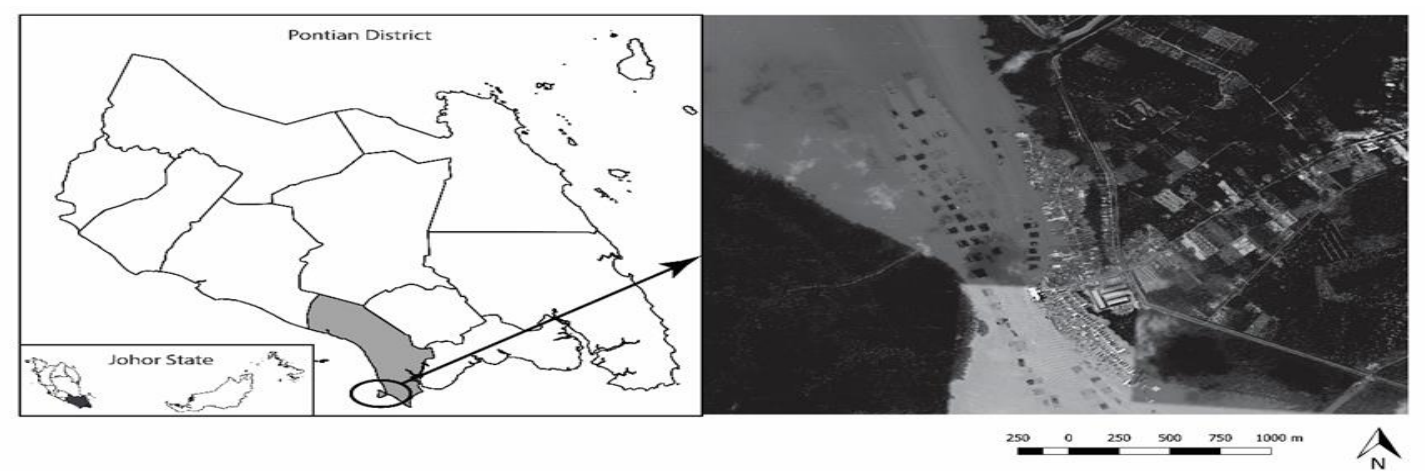

Fig. 1: Ayer Masin and Kukup Laut water village on the Straits of Kukup, Malaysia 


\section{RESULT}

\subsection{THE DRIVERS OF SPATIAL DEVELOPMENT}

Buildings were the earliest human-made structures to two villages, which included house, fishing workshop and jetty. Initially, the buildings were built randomly above the water but had gradually clustered around strategic locations for accessing the sea. The spatial development, shown in Fig. 3, demonstrates the implication of geographical features on the formation of Kukup settlement. According to the interviewees, Kukup Laut village was initially built adjacent to the port, which has existed since the 1860s. The village expanded southward from the port and the buildings were densely distributed along the coast. Conversely, the original location of Ayer Masin village was located at the estuary of the Permas River on a west-east direction, and the buildings were clustered along the riverbank but gradually expanded southward. Although this spatial development may be attributed to seeking natural shelter from Kukup Island, the interviewees disagreed but stated that the construction plan was to stay close to the port for the ease of mainland access.

According to the data collected from the interviewees, the study categorises the causes of spatial development into natural, socioeconomic and cultural drivers:

1) Natural drivers: Living above water brings constant challenges to the inhabitants due to coastal risks and hazards. In particular, mudslides, erosion and flooding have significantly affected the settlement's spatial development. According to the interviewees, Kukup Laut experienced a mudslide in 1981 that caused around ten houses to collapse. Due to safety concerns, the villagers decided on a reconstruction site at the rear of existing houses in order to stay away from tides. The spatial layout of Kukup Laut has changed tremendously after the incident. Formerly, the villagers used boats to approach other houses, but the new construction site was inaccessible by boat. Consequently, wooden pathways were rapidly constructed to connect houses. After the reconstruction, new buildings were generally built along the pathways and neatly arranged in layout. Further to this, flooding regularly occurs in the wake of high tides, sometimes lasting for several days during the rainy season. Together with the challenge of coastal erosion, the village faces double strikes from land subsidence and coastal flooding.

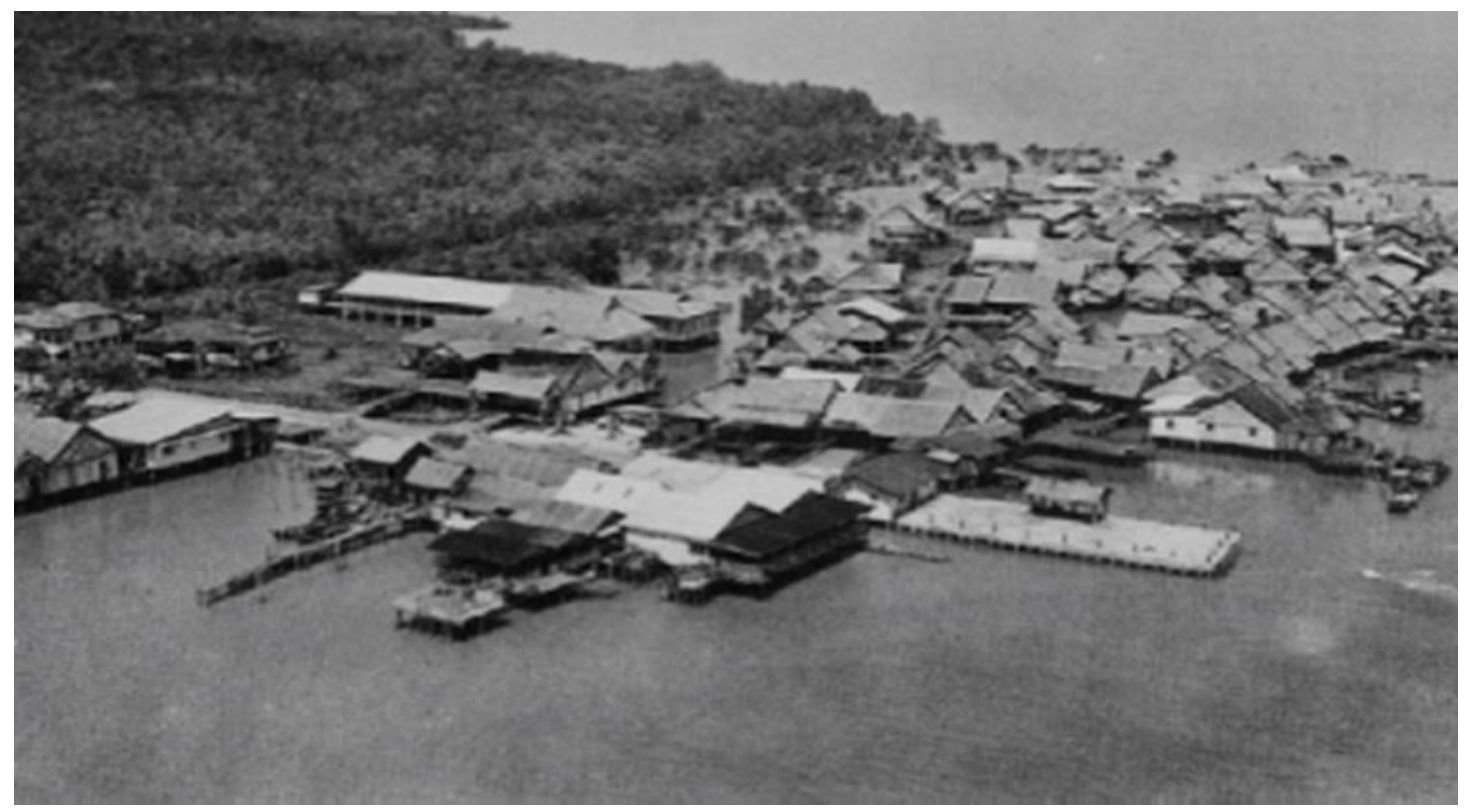

Fig. 2: Historical photo showing the spatial layout of two Kukup villages in 1970

2) Socioeconomic drivers: Political decisions made concerning the villages influenced the spatial development between the 19th and 20th centuries. Kukup had played an important economic and administrative role following the launch of the Southwest Coast of Johor's reclamation project in 1878 (Said, 1977). Kukup 
was given the privilege of issuing its monetary note and was classified as a district. Infrastructure development including harbour and roads connecting the settlement to land followed the rapid economic growth. Also, the project brought in Chinese manual labourers, many of whom had settled in Kukup. Policy incentives, employment opportunities, infrastructure and transportation, contributed to the formation and expansion of the villages. Ayer Masin had been isolated from the land before the road was built in the 1920s, and houses were randomly distributed along the Straits of Kukup. The construction of the road connecting harbour and mainland encouraged spatial development towards the south to secure access to the mainland. Besides, an administrative order in the 1940s had further facilitated spatial development. Due to postWWII chaos and communist activity, the newly independent government required a stiltsupported pathway to be constructed linking Ayer Masin to the mainland in order to strengthen monitoring and communication. Since then, buildings in Ayer Masin have been built parallel to the pathway towards the harbour, but no longer clustered along the estuary of the Permas River.

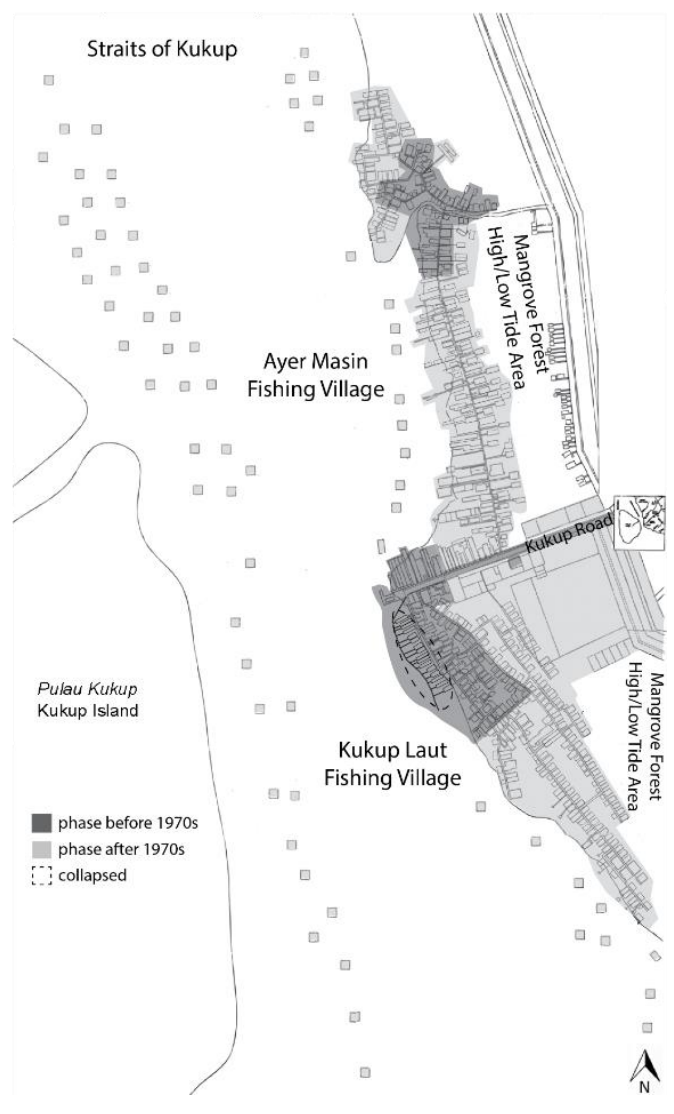

Fig. 3: Spatial development of Kukup Laut and Ayer Masin before and after 1970

Cultural drivers: Religion and religious buildings play a significant role in the villages' spatial development. Temple as a physical structure provides clues to trace the stages of spatial development in the settlement. It serves not only a place of worship but also accommodates social activities, such as village meeting, socialising and sports activities. The study identified the earliest set of buildings clustered around the oldest temple in both of the villages. Additionally, new constructions and expansions were often accompanied by temple construction. Temples were situated at each of the main pathway nodes in Kukup Laut; conversely, in Ayer Masin, temples were distributed along the main pathway at an averaged distance.

Another significant aspect of cultural influence was the local perception of risk and hazards; a useful example of this is the local community's outlook on flooding. Despite realising the potential damage caused by floods, the interviewees perceived flooding as part of their routine life. As a shop owner said:

When I was a kid, I always looked forward to the raining season. The road was flooded...so we the kids can swim or ride sampan ('wooden boat' in Malay) on the road. Now, I am still pleased to see kids playing water as we did when it is flooded.

The spatial development of buildings reflected the positive perception of flooding. The buildings have been continuously elevated above the water to prevent the incursion of water into the houses, but the interviewees did not see flooding as a motivation for moving or evacuation to land.

\subsection{LOCAL ADAPTIVE MEASURE TO COMBAT COASTAL RISKS AND HAZARDS}

The building is the fundamental unit of water settlement and reflects local measures of adaptation to living with coastal risks and hazards. This section describes the essential elements of water building, followed by an analysis of building expansion and construction that endeavours to adapt to the coastal environment. Generally, a water building, shown as Fig. 4, consists of: 


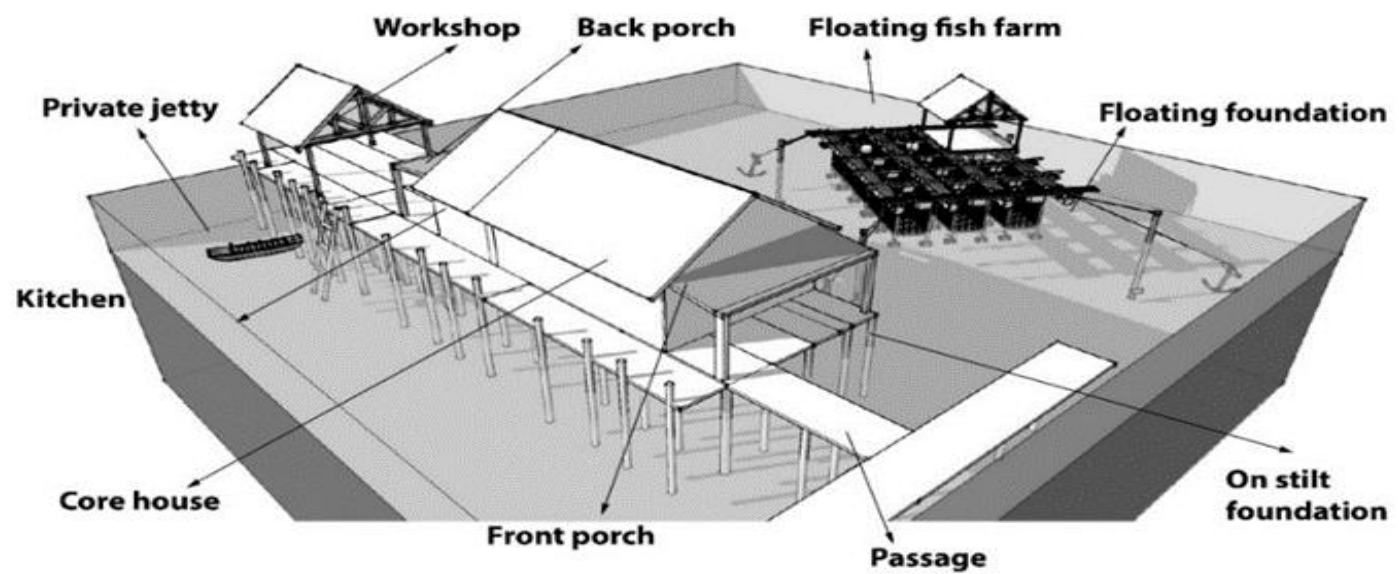

Fig. 4: Elements of water building in Kukup settlement

i. Foundation: Water building is built on stilts to adapt to the coastal settings. The building is elevated an estimated eight feet from the ground to allow water to flow and the growth of wetland vegetation underneath.

ii. Core house: Where most activities are conducted. Different from traditional Malay and Chinese house, the height of the core house is similar to the other parts of the house.

iii. Kitchen: Wet area of the house.

iv. Front porch: Main entrance of the building and parking for bicycles and motor vehicles. Some of the front porch in the villages were converted to coffee shops, grocers, or family craftwork stalls. v. Back porch: Second entrance of the building for fire evacuation.

vi. Workshop: Connected to the core house by a passage and built at a strategic location for water access. This is where the household carries out fish processing and also provides storage.

vii. House jetty: Da-tou in Min Nan dialect. It is paired with the workshop as the gateway for accessing the sea and for boat parking.

viii. Passage: Connect the village pathway and each house as a transition space between public and private domains.

ix. Fish farm: Floating structure to adapt to waves and tides.

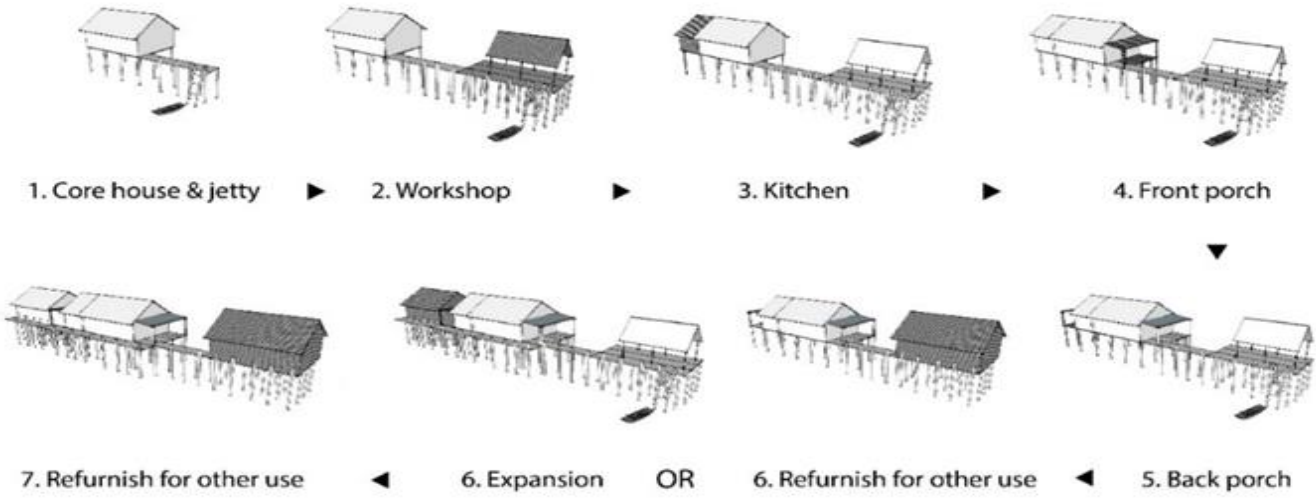

Fig.5: Expansion phase of water building. Left: workshop at front; right : workshop at the rear

The method of building expansion, including the direction of expansion and the use of the building, reflects the relationship between the livelihood and the coastal environment (see Fig. 5). Generally, a water house contains a passage linking it to the open water where boats were parked. The passage can be built either at the front or at the rear of the house. Accessibility to the open water, therefore, determines the direction of expansion. The fishing workshop and kitchen are commonly adjacent to the front and back porch. Over the past 50 years, many 
workshops have been repurposed into hostels or additional family space due to a shift in economic activities from fishing to fish farming and tourism.

The construction methods of water building reflect the adaptive measures used to adapt to the coastal setting, including pile structures, floating structures and the materials used.

i. Mangrove pile structure (see Fig. 6): The earliest method of water building using mangrove timber. The piling construction follows the tidal cycle and can be only carried out during low tide. The logs were manually piled into the mudflat, spaced at a distance of 6 to 8 feet. The logs were tied in cross shapes and were piled five feet under the mudflats. The cross-shaped method was perceived to help stabilise the pile in the mudflats. According to the interviewees, the villagers applied the crossshaped technique after realising a pile without the cross shape were unstable - either sank or floated. The villagers selected mangrove for pile structure because of its natural ability to adapt to seawater. However, mangrove is not strong enough to support a big building. Therefore, the buildings were often limited to one storey in height and constructed with light-weight materials, such as timber and leaves. The piles had to be replaced every several years to ensure building safety.

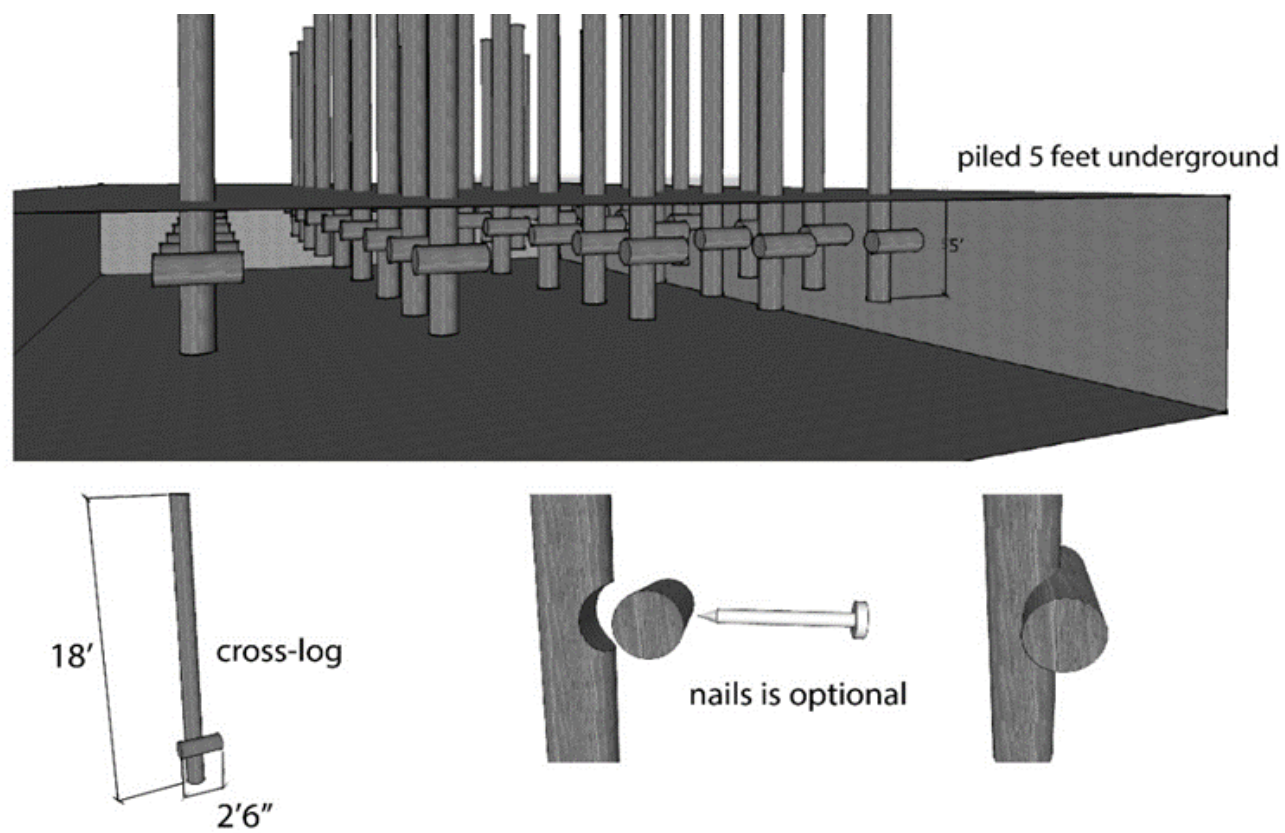

Fig. 6: Mangrove pile structure in cross shape

ii. Concrete pile structure (see Fig. 7): The structure combining mangrove and cement improved the durability and safety of water building considering the natural adaptive character of mangrove and the massive loadbearing capacity of cement. Each set of mangrove logs, consisting of 12 to $15 \operatorname{logs}$, was piled entirely underneath the mudflat. Above each mangrove base, cement was used to build a concrete pile.

iii. Areca pile structure (see Fig. 8): Also known as kelong in the Min Nan dialect. This structure was used for offshore fishing activities. It required two divers to work under the sea accompanied by two construction workers above the water. The divers fixed the pile in the required position while the construction workers piled the logs five feet underground. A Kelong platform consisted of two floors, of which the first floor was for setting up fish traps and the second layer was designed for operation. Areca $\operatorname{logs}$ were used for kelong because of their length; however, they were fragile and needed to be replaced every few years.

iv. Floating structure (see Fig. 9): Due to water pollution and a decrease in fish catch rates, kelong were gradually replaced by floating fish farms during the 1970s. Construction was conducted on land, and the building would be moved to open water on completion. Various types of timbers were tied above plastic buckets. A fish farm is equipped with an anchor and tied to cross-shaped mangrove piles at the four corners to stabilise it against waves. 


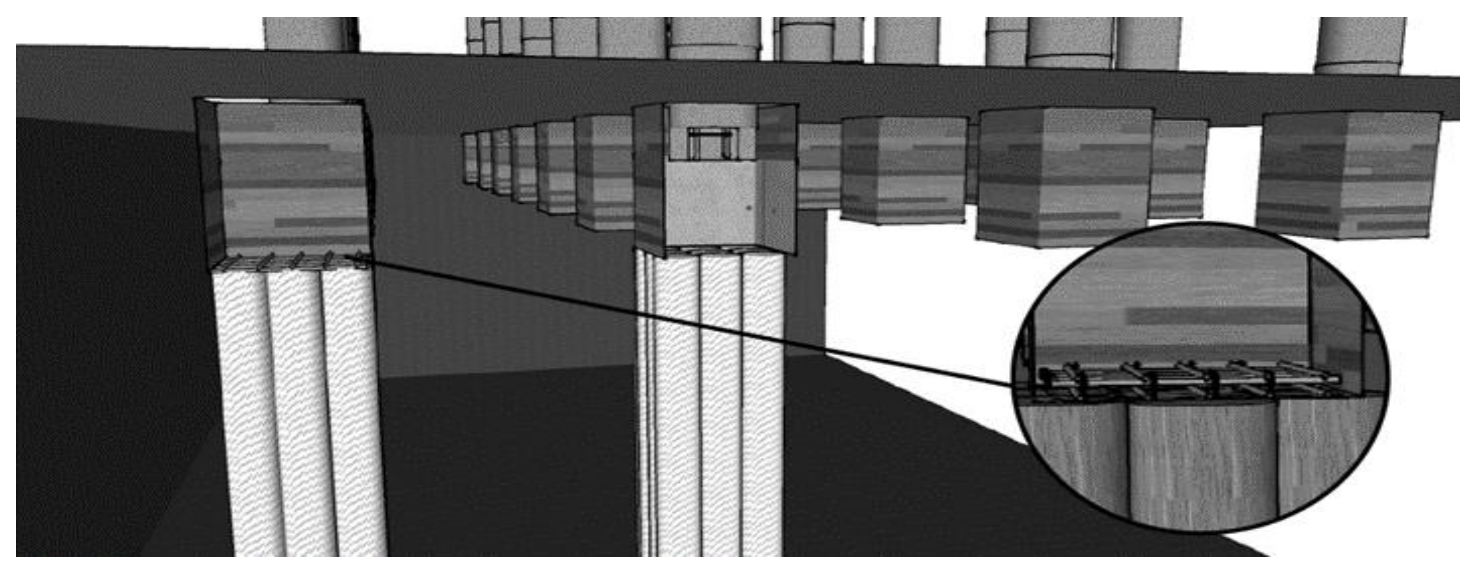

Fig. 7: Concrete pile structure using mangrove and cement

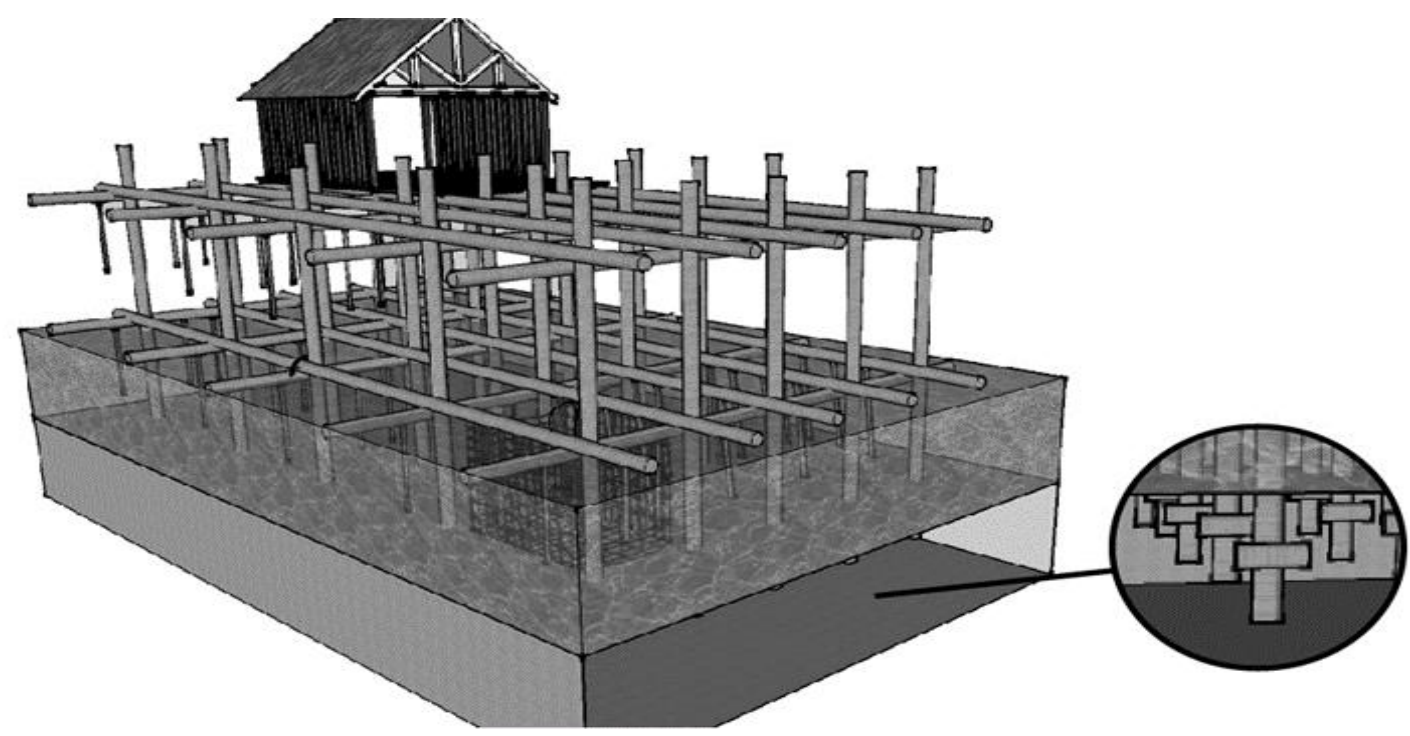

Fig. 8: Offshore Areca pile structure for a Kelong

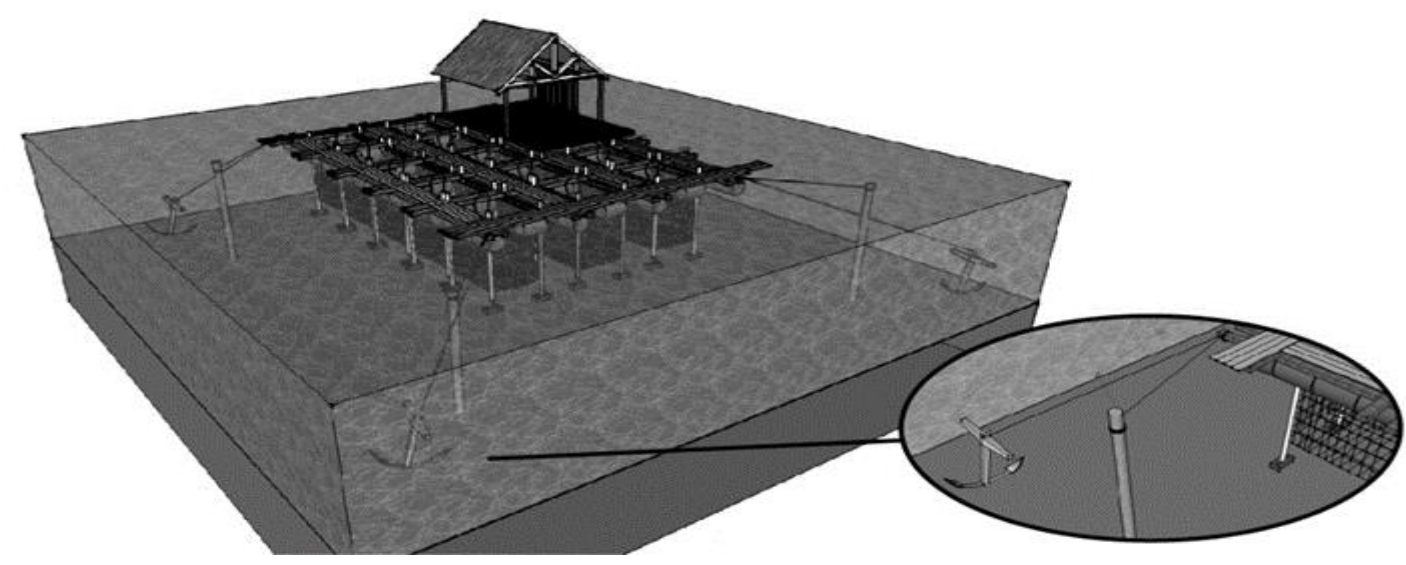

Fig. 9: Floating structure of fish farm

\subsection{THE DETERMINANTS OF LOCAL ADAPTIVE CAPACITY}

In order to address and improve societal adaptive capacity, community-scale practices are expected to contribute to the reduction of people's vulnerabilities (Barry Smit \& Wandel,
2006). Multiscale conditions contributing to the community's access to financial, technological and information resources, infrastructure, and institutional environment have a critical influence on local adaptive capacity (Kelly \& Adger, 2000; Wisner, Blaikie, Cannon, \& Davis, 2004). Overall, the study identifies cultural 
drivers have influenced the local adaptive capacity of Kukup villages with two aspects, which were, however, comparatively underexplored:

i. Information access: In recent years, mangrove conservation on Kukup Island and along the Straits of Kukup has been conducted to protect the mangrove ecosystem and to reduce erosion. The interviewees reported the impact of conservation activities on their livelihood, including the restriction of new building construction and mangrove logging. However, the interviewees did not fully understand the purpose of mangrove conservation. The study finds the information regarding conservation activities was mostly written in Malay or English, which was inaccessible for the villagers, given that most of the villagers spoke Min Nan or Mandarin. Also, the villagers tended to access information through the temples, irrespective of the fact that a conservation office has been set up in the village. Understanding the network of information access is therefore identified as a vital aspect of an accurate assessment of local adaptive capacity.

ii. Local perception of risks and hazards: Living with water has been part of the collective memory for the water community and contributes to the formation of individual's and community's identity. A complex combination of broader societal settings and informal components, such as family networks and personal experience has shaped the local perception of risks and hazards. For example, when talking about the challenge of living on the sea, the interviewees generally acknowledged the impact of flooding and erosion but highlighted their concerns over water pollution. An in-depth investigation is needed to understand better how local people perceive different types of risk and hazards and how this reflects on local adaptive capacity (see Fig. 10).

Local adaptive capacity is context-specific and varies from community to community. Depending on economic, social, technological and cultural resources, communities can adapt to moderate climatic conditions, but exposure to extreme events may exceed the adaptive capacity of the community. However, understanding the determinants of local adaptive capacity is essential in order to better design and assess adaptation strategies and measures, and thereby reduce the vulnerability of people and communities within coastal regions.

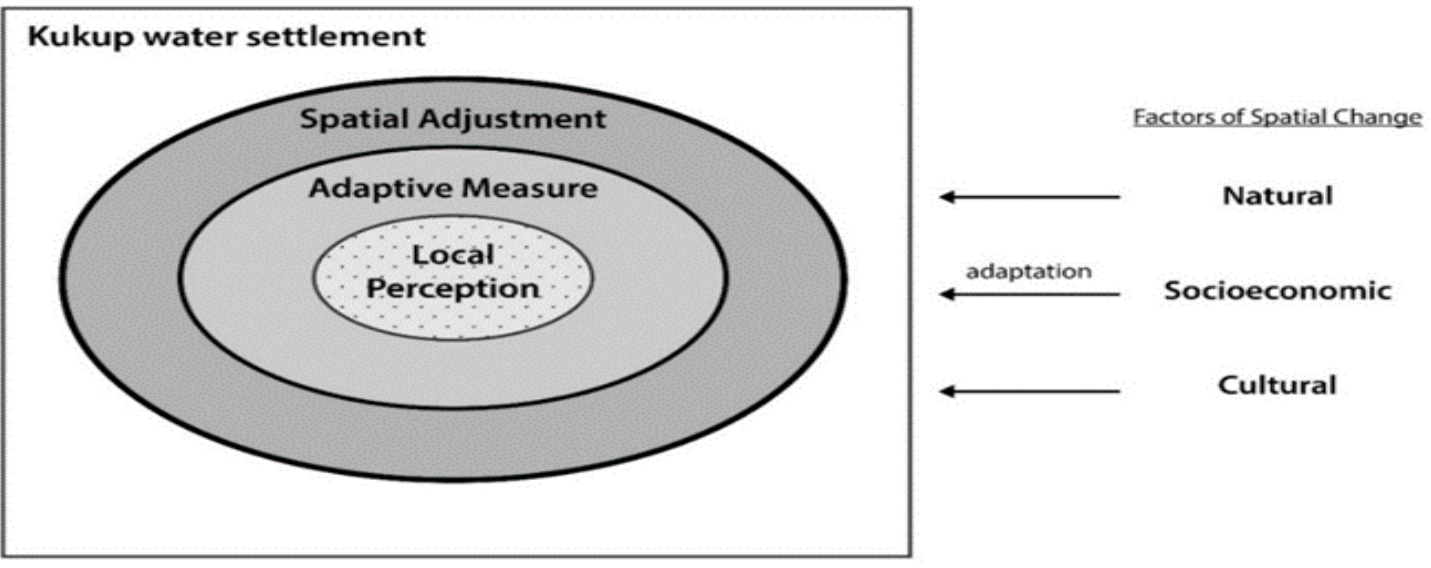

Fig. 10: Local perception as an essential factor that influences local adaptive capacity

\section{CONCLUSION}

Social scientists have widely applied the concept of adaptation in considering the relationship between ecosystem, political economy and social relations (Burton, Kates, \& White, 1978). Numerous studies have improved the understanding of how adaptive capacity is related to the social, economic and political settings that accommodate individuals or households. Concerning this, several researchers have addressed the effects of human driving forces in adjusting environmental risk and contributing to vulnerability reduction (Kasperson \& Kasperson, 2001; Pidgeon, Kasperson, \& Slovic, 2003).

Until recently, there has been little interest in cultural perspectives of climate change adaptation. In the cultural ecology studies, Butzer (1989) introduced an application of the term "cultural adaptation", which was originally used by the anthropologist and cultural ecologist 
Julian Steward, to describe how "culture cores" are adjusted to respond to one's natural environment through subsistence activities. Other researchers, for example, Denevan (1983) and O'Brien and Holland (1992), have also investigated the process of cultural response to physical environmental change. However, few empirical studies have addressed the relationship between cultural factors and adaptive capacity. Given that the coastal population is expected to increase continuously (Neumann et al., 2015), further research is needed in order to understand the effects of cultural factors on adaptive capacity and how it can contribute to an improvement of adaptive capacity that is sensitive to varying social context.

\section{ACKNOWLEDGEMENT}

This research project was supported by NCKU Overseas Student Scholarship. We gratefully appreciate the support of all the interviewees and the assistance provided by Kukup Laut water village and Ayer Masin water village and the comments of the anonymous reviewers of this paper submission.

\section{REFERENCE}

Aerts, J. C. J. H. (2012). Climate Adaptation and Flood Risk in Coastal Cities: Earthscan Canada.

Ang, C. C. (2007). Biografi Tokoh-Tokoh Cina Daerah Pontian. Pontian: Ang Chor Chew.

Barbier, E. B., Koch, E. W., Silliman, B. R., Hacker, S. D., Wolanski, E., Primavera, J., . . . Reed, D. J. (2008). Coastal Ecosystem-Based Management with Nonlinear Ecological Functions and Values. Science, 319(5861), 321.

Burton, I., Kates, R. W., \& White, G. F. (1978). The Environment as Hazard: New York, Oxford University Press.

Butzer, K. W. (1989). Cultural ecology. Geography in America, 192-208.

Dasgupta, S., Laplante, B., Meisner, C., Wheeler, D., \& Yan, J. (2009). The impact of sea level rise on developing countries: a comparative analysis. Climatic change, 93(3), 379-388.

Denevan, W. M. (1983). Adaptation, variation, and cultural geography. The Professional Geographer, 35(4), 399-407.

FitzGerald, D. M., Fenster, M. S., Argow, B. A., \& Buynevich, I. V. (2008). Coastal impacts due to sea-level rise. Annu. Rev. Earth Planet. Sci., 36, 601-647.

Frings, M. (2011). Indonesia's Role in International Climate Policy: Financial incentives to preserve the rainforest - an effective model? Retrieved from KonradAdenauer-Stiftung Country office to Indonesia and Timor-Leste: http://www.kas.de/indonesien/en/publicatio $\mathrm{ns} / 22540 /$

Grothmann, T., \& Patt, A. (2005). Adaptive capacity and human cognition: the process of individual adaptation to climate change. Global Environmental Change, 15(3), 199213.

Hassan, A. S. (2010). Review on old city landscape with reference to traditional fishing village settlements in western coastal region, Peninsular Malaysia. Jurnal of Human Settlements, 2(1), 1-10.

Jones, H. P., Hole, D. G., \& Zavaleta, E. S. (2012). Harnessing nature to help people adapt to climate change. Nature Clim. Change, 2(7), 504-509.

Kadir, A. B. A. (1955). Hikayat Abdullah: Oxford University Press.

Kasperson, R. E., \& Kasperson, J. X. (2001). Climate change, vulnerability, and social justice: Stockholm Environment Institute Stockholm.

Kelly, P. M., \& Adger, W. N. (2000). Theory and practice in assessing vulnerability to climate change andFacilitating adaptation. Climatic change, 47(4), 325-352.

Klein, R. J. T., Nicholls, R. J., \& Mimura, N. (1999). Coastal adaptation to climate change: can the IPCC Technical Guidelines be applied? Mitigation and Adaptation Strategies for Global Change, 4(3), 239252.

Liz, C. (2003). Ripple effects: population and coastal regions. Retrieved from Washington, USA:

McGranahan, G., Balk, D., \& Anderson, B. (2007). The rising tide: assessing the risks of climate change and human settlements in low elevation coastal zones. Environment and Urbanization, 19(1), 17-37.

Mukherjee, N., Balakrishnan, M., \& Shanker, K. (2009). Bioshields and Ecological Restoration in Tsunami-Affected Areas in India Integrated Coastal Zone Management (pp. 131-144): Wiley-Blackwell.

Neumann, B., Vafeidis, A. T., Zimmermann, J., \& Nicholls, R. J. (2015). Future coastal population growth and exposure to sea-level rise and coastal flooding-a global assessment. PLoS ONE, 10(3), e0118571.

Nicholls, R. J., \& Tol, R. S. J. (2006). Impacts and Responses to Sea-Level Rise: A Global Analysis of the SRES Scenarios over the Twenty-First Century. Philosophical Transactions: Mathematical, Physical and Engineering Sciences, 364(1841), 1073- 
1095.

O'Brien, M. J., \& Holland, T. D. (1992). The role of adaptation in archaeological explanation. American Antiquity, 57(1), 36-59.

Pidgeon, N., Kasperson, R. E., \& Slovic, P. (2003). The social amplification of risk: Cambridge University Press.

Risbey, J., Kandlikar, M., Dowlatabadi, H., \& Graetz, D. (1999). Scale, context, and decision making in agricultural adaptation to climate variability and change. Mitigation and Adaptation Strategies for Global Change, 4(2), 137-165.

Said, S. (1977). Kegiatan keluarga Alsagoff dalam ekonomi negeri Johor 1878-1906 [in malay]. Malaysian Journal of History, Politics and Strategic Studies, 07(08), 5267.

Smit, B., Pilifosova, O., Burton, I., Challenger, B., Huq, S., Klein, R. J. T., . . O Of. (2001). Adaptation and Vulnerability, contribution of working group II to the third assessment report of the intergovernmental panel on climate change: Adaptation to climate change in the context of sustainable development and equity. Cambridge University Press. UK, Cambridge, 877-912.

Smit, B., \& Wandel, J. (2006). Adaptation, adaptive capacity and vulnerability. Global Environmental Change, 16(3), 282-292.

Smith, K. (2011). We are seven billion. Nature climate change, 1(7), 331.

UNEP. (n.d.). Cities and coastal areas. Retrieved from http://staging.unep.org/urban environment/ issues/coastal zones.asp

VanKoningsveld, M., Mulder, J. P. M., Stive, M. J. F., VanDerValk, L., \& VanDerWeck, A. W. (2008). Living with sea-level rise and climate change: a case study of the Netherlands. Journal of Coastal Research, 367-379.

Wisner, B., Blaikie, P., Cannon, T., \& Davis, I. (2004). At risk. Natural hazards, people's vulnerability and disasters, 2. 